\title{
Role of brain serotonin in age-related decline in physical activity in mice
}

\author{
P.B. Martinez de Morentin, M. Arcon, A. Leeson-Payne, Y. Martynova and L.K. Heisler \\ The Rowett Institute, University of Aberdeen, Aberdeen, UK
}

Ageing is negatively correlated with physical activity (PA) and this has an undesirable impact on overall health ${ }^{(1)}$. The neurotransmitter serotonin (5-HT) is known to be inversely correlated with physical activity ${ }^{(2)}$. Here we investigate a serotonergic neuronal circuit involved in voluntary physical activity during ageing in mice.

We injected designed DREADD proteins (Designer Receptors Exclusively Activated by Designer Drugs) that enable non-invasive control of neuronal signalling through the Gq (hMD3q, excitatory) and Gi (hMD4i) G-protein coupled signalling pathways in the dorsal raphe nucleus (DRN) of Tph $2^{\mathrm{iCre}}$ mice (tph2, rate-limiting enzyme in 5HT synthesis) to modulate 5-HT release, or in the ventral segmental area (VTA) of 5- $\mathrm{HT}_{2 \mathrm{C}} \mathrm{R}^{\mathrm{Cre}}$ mice (5-HT type $2 \mathrm{c}$ receptor) to modulate activity in a 5-HT target region. Upon administration of CNO (clozapine-N-Oxide, Designer drug for DREADD) (1mg/kg, IP) and lorcaserin (3mg/kg, IP) we characterised the locomotor activity profile of all mice using TSE Phenomaster.

Our results showed that activation of Tph $2^{\mathrm{DRN}}$ cells reduced PA $(\mathrm{p}<0.05 ; \mathrm{Veh}, \mathrm{n}=11,12811 \pm 1554 \mathrm{vs} \mathrm{CNO}, \mathrm{n}=108196 \pm 2821$, $\mathrm{t}=2.507, \mathrm{df}=19$, $)$ while its inhibition induced locomotion $(\mathrm{p}<0.001 ;$ Veh, $\mathrm{n}=5,13209 \pm 1181, \mathrm{vs} \mathrm{CNO}, \mathrm{n}=5,26948 \pm 2515, \mathrm{t}=$ $4.944, \mathrm{df}=8$. Chemogenetic activation of $5-\mathrm{HT}_{2 \mathrm{C}} \mathrm{R}^{\mathrm{VTA}}$ reduced PA $(\mathrm{p}<0.05, \mathrm{Veh}, \mathrm{n}=6,6650 \pm 1329$ vs $\mathrm{CNO}, \mathrm{n}=9,3587 \pm 401$, $\mathrm{t}=2.606, \mathrm{df}=13)$ while its inhibition reverted the effects of lorcaserin $(\mathrm{p}<0.01$, Lorc + veh $\mathrm{n}=6,10704 \pm 1235$ vs Lorc + CNO $\mathrm{n}=9,16280 \pm 1405, \mathrm{t}=2.930, \mathrm{df}=11)$

In summary, our data indicate that the serotonin system through the 5-HT2cR signalling in the VTA is involved in the control of locomotion and identify a means to reverse age-related decline in physical activity.

\section{Acknowledgments}

This work was supported by the BBSRC (BB/R01857X/1 and BB/N017838/1) and The Royal Society of Edinburgh (RSE1122).

\section{References}

1. Gulsvik AK et al. (2012) Int J Epidemol 41(2), 521-530.

2. Fonseca MS, Murakami M \& Mainen ZF (2015) Curr Biol 25, 306-315. 